\section{Introduction and Suemary}

The ISABELLE design curfent is built up by repetitive cransfer of charge frow the dGS. To do this, a momentun scacking werhod stallar to the one used at the ISR has been chosen. The ACS boam bunches are synchronousiy cransierred from the ACS into waliting if buckets on the infection orbit at the ISA, and then slowly accelerated into the previously established debunched beam stack. This process is repeaced until all the avallable momentum aperture in the ISA 18 El!lad up, whereupon the beam stack is rebunched and accelerated to the desired operating energy.

ISABELIE is located to the north of the ACS in suc" a way that an existing bear extraction system and part o: in existing experimental bean transport cunnel can be used. The dGS extraction sustem is being redesigned to assure precise fast extraction, of the required number of AGS bunches. The extracted beam is directed coward one of the ISA scra1ght sections ("5 $0^{\prime}$ clock") and then bent toward the outer arcs of the two ISABELLE rings (see Fig. 1). The ISA Injeccion system deposits the beam on the proper orbit in the ISA vacuum chamber. In the following, each of these three s!stems 's described in curn. The synchronizacion of the aGS and the ISA and the accuracy zequirements for the beam transfer process are discussed in the last section.

2-1078-79

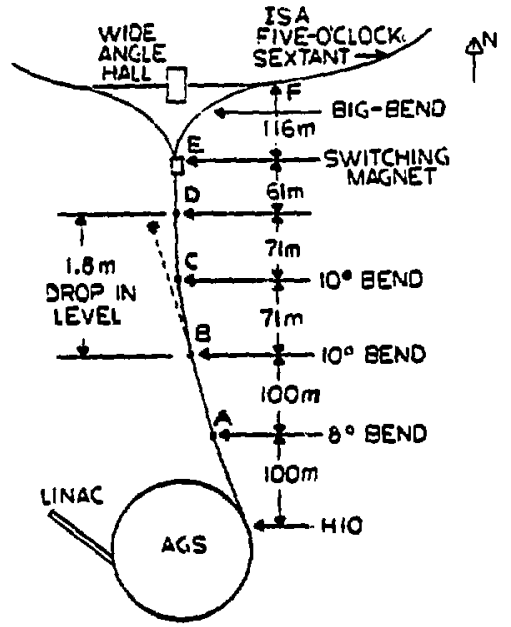

Fig. 1. Schematic layout of the AGS-ISA beam transfer geonetry.

The infection line described here supercedes the earlier design published in the new 1978 ISABELLE Proposal. I

\section{AGS and ISA Parameters}

The dGS if system operaces at the 12th harmonic of the revolution frequency and it will be synchronized with the ISA stacking $z \dot{t}$ system which will accept bunchis from che ACS at the same frequency. The circumference of the ISA ring is 4.75 times that of

\footnotetext{
"Work dore under the auspices of the U.S. DOE.

Brookhaven Sational Laboracory, Upeon, i.S. 21973.
}

the AGS, thus the stacking syster has harmonic number $h=57$. It is proposed to extract 21 acs bunches at a tiwe (the 12th being knocked out prlor to AGS acceleration) five times in succession to f1ll 55 of the 57 walting ISA buckets. These 55 bunches are acceleraced toward the momentum stack. This process requires several hundred AGS pulses to achleve the design current of 8 i $6 \times 10^{14}$ protons) in each ring.

The parameters of the AGS, when used as an ISA infector, are summarized in Table $t$. It is thought that the high beam brightness in transverse phase space is best obcained by running the AGS at relatively low incensity.

\section{Table I. AGS Parameters}

$\begin{array}{ll}\text { Energy } & 29.4 \mathrm{GeV} \\ \text { Intensity/Pulse } & 2.7 \times 1.0^{12} \\ \text { Yomentum Spread } & =0.5 \times 10^{-3} \\ \text { Vert1cal Emittance } & 0.5 \pi \times 10^{-6} \mathrm{rad}-\mathrm{m} \\ \text { Hor1zontal Emittance } & 0.5 \pi \times 10^{-6} \mathrm{rad}-\mathrm{m} \\ \text { Longltudinal Emitcance } & 1.06 \mathrm{eV} \mathrm{sec} / \text { bunch }\end{array}$

Iigure 2 sumarizes the utilization of the ISA apercure $(88 \mathrm{~mm})$ at a point in the lactice where the momentum dispersion is at a maximum. The widch of the full beare stack corresponds to a momentum spread of $1 \%$ Eull width.

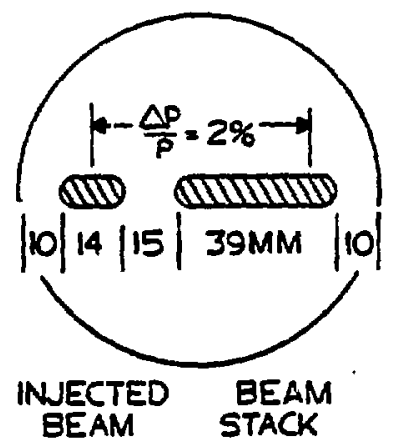

$3-32-79$

Fig. 2. Aperture utilization at the infection kicker.

\section{Excraction Erom the AGS}

The configurtetion of the proposed new AGS extraction system is outlined in Fig. 3. Before extraction a local $3 / 2$ wavelength orbit deformation will bring the clrculating proton beam 1nto the aperture of a C-type fast k1cker magnet (KM) located at strafght section H5. The same bump will also align the beam as close as possible to the efector septum (EM) locaced at HiO. At extracrion the kicker magnct will be powered to kick the bean into the aperture of the Ex, which in turn deflects the beam out of the AGS. At the stralght seccion HI3 the separation of the sxternal beam and the ctrculating beam is about $43 \mathrm{~cm}$ and the dGS magnet friuge fleld is negligible. Therefore, it is convenlent to consider this location as the exit point from the AGS. An existing extenston of this line, incorporacting a $4^{\circ}$ bend and a superconducting $8^{\circ}$ bending nagnet, direct the beam out of the AGS tunnel toward the Sorth. The only new components in this system to be bullt in the iurure are the fase kicker kil at 45 stralght section, and the local orble bump. Ill ocher components and faciltties already exist. 


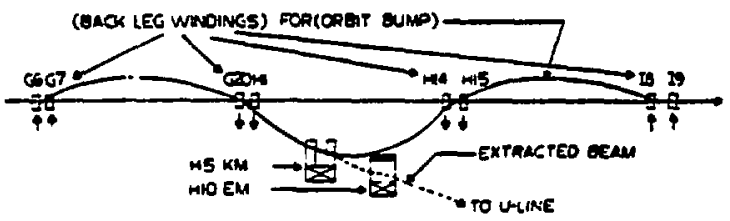

F1g. 3. The sketch of the proposed AGS new fast excraction orbits and componeats.

To provide clean single turn extraction the fast kicker will rise co full Eleld in 150 nsec, 1.e. less than the bunch to bunch separation of $225 \mathrm{nsec}$. The Fast kicker deflection angle will be $1.2 \mathrm{mrad}$ at 29.4 GeV energy, and the flat top of the kicker will be constant to within approximately $=1 \%$.

The theoretical ealttance parameters of the exrracted beam at the extraction point $\mathrm{HI}_{13}$ are summarized in Table II.

\section{Iable II. Paraweters at HI3 Fast Extracted Beam}

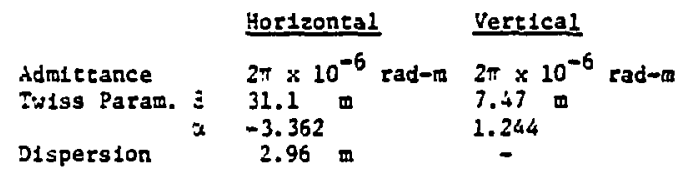

The large admittance value makes allowance for iull incensity AGS operation. The morencum dispersion is not zero at the extraction point, ${ }^{2}$ but it is desirable to cancel the dispersion in the long stralght portlons of the subsequent beam transfer channel. Between the $4^{\circ}$ and the $8^{\circ}$ bend in this early part ot the transport Iine there are five quadrupoles which are adjusted In such a way that the beall 15 well confined to pass safely through the superconduceing magnet aperture, and is achromatic at 1 ts exit.

\section{Bean Transfer AGS-ISA}

In this section we discuss the beam transfer proper between the exit of the $8^{\circ}$ bend near the ACS and the special infection magnet system at the ISt. The be in is dispersion-free at the beginning of this line anc by the time it reaches the ISA injection point, It must be matched in all aspects to the parameters of the ISA lactice. The geometry of the transport line is 11lustrated in F1g. 1. In the hortzontal plane the beam has to be deflected twice; first to ain toward the ISA straight section eenter $\left(2 \times 10^{\circ}\right.$ bend $)$ and again towards the two injection points ( $81.5^{\circ}$ bend). In the vertical plane it is nesessary to overcome an elevation difference of $1.8 \mathrm{~m}$

The injection geometry described differs from the earlier published plans in that only one stralght section (rathar than two) is used and the Iiljection line is not seen at all by the users of the experimental ha11. To accomplish this the ISA rings were rotated $30^{\circ}$ compared to the $1978^{\circ}$ design proposal.

For each $10^{\circ}$ h.jrizoncal bend, we use four $3 \mathrm{~m}$-long dipoles with field strength $~ 1.4 \mathrm{~T}$. For the vertical pltchlng, we use two small dipole magnets. Each of them $1 \mathrm{~s} 1.5 \mathrm{~m}$ long and capable of bending 12.7 mrad. The vertical drop stares at the same position as the first $10^{\circ}$ horlizontal bend. In order to make the two $10^{\circ}$ horlzontal bends achromat $1 \mathrm{c}$, the phase advance between them 13 made to be exacty $180^{\circ}$ and for the same resson the phase advance between two vertical bends is exactly $360^{\circ}$.
This is achieved by placing eight quadrupoles from points $B$ tO D in a FODO pactern (see Fig. 1). Each quadrupole is 0.7 m long with fleld gradient $G$ $=9.5 \mathrm{~T} / \mathrm{m}$. Thus in the space between $B$ and $D$, thetre are tour FODO cells with phase advance per cell $90^{\circ}$ and cell length $35.5 \mathrm{~m}$. Beyond point $D$ the beam is again dispersion free and the stralght space between $D$ and $z$ of $60 \mathrm{~m}$ is used for matching into the b1g-iend.

At the beginnting of the big-bend is a switching dipole which is capable of sultching the Incoming beam e1ther into the right arc or the left arc of the bisbend. Fron $E$ to $F$ the total length of the big-bend is $174.4 \mathrm{~m}$. The total angle of bend is $81.5^{\circ}$ and the average radius of curvacure is $105 \mathrm{~m}$.

Th1s part of the transfer is achleved by eight FODO cells too. The lactice structure of a unte cell is 11lustrated in F1g. 4. AgaIn, the phase advance per cell is $90^{\circ}$ with quadrupole of length $0.8 \mathrm{~m}$ and excitation of $G= \pm 20 \mathrm{~T} / \mathrm{m}$. The cell length is $1.8 .5 \mathrm{~m}$ and between quadrupoles there are bending magnets of 6 in long with 1.7 I excitacion. As shown in F1g. 4, the maximum betatron Eunction in the cell is $30 \mathrm{~m}$ in both planes and the meximum nomencum dispersion function is $2.3 \mathrm{~m}$. If we split the dipole into two pleces, the maximur sagitta
in $3 \mathrm{~m}$ is $1 \mathrm{~cm}$.

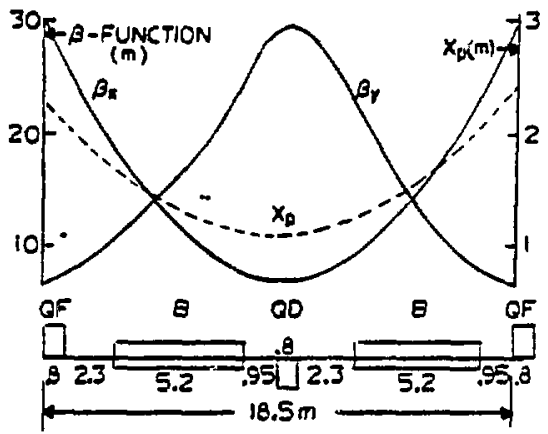

F1g. 4. Unit cell structure of the big-bend.

The final cell upstrear of the first thin septum magnee for injection is slighely modified in order to match up the betatron function of the ISA iattice. To the E1rst order approximation, we only have to omit the bending in the last cell to watch the momentum dispersion function; however, in acrual cesigr there are two sarall dipoles for guaranteelng the exact dispersion ratch. Iwo meters upstrean of the first septum magnet (F18. 5), the dispersion function is zero. Here a small steering magnec is introduced to direct the offmonentum injected beam into the correct orbit in the ISA.

For the consideration ci physical aperture or the magnets, we assume that the emltrances in both horizontal and vertical planes are $2 \pi \mathrm{\mu r}-\mathrm{rad}$ at $30 \mathrm{GeV} / \mathrm{c}$ and intensity $10^{13} \mathrm{ppp}$. The momentum acceptance of the transfer line is assumed to be $\Delta p / p= \pm .3 \%$ frow the AGS to point $D$ and $=1 \%$ from $D$ to the ISA. Thus the b1g-bend section can accommodate the entire acceptance of the ISA. This reserves flexibility for later developments. The resultant maximum aperture needed for the dipole magaets from $A$ to $D$ is $3 \mathrm{~cm}(V) \times 10 \mathrm{~cm}(\mathrm{H})$ and that from $E$ to ISA is $3 \mathrm{~cm}$ (V) $\times 12 \mathrm{~cm}$ (H).

\section{ISt Injection}

The bean 1 is Inserted Into the outer arcs of the ISA ut1l1zing the iree spaces between the quadrupoles Q5-Q7 in the dispersion matching section between the stralght section and the regular ISA bending lattice. F1gure 5 11lustrates the rechod. The bean approaches 
the ISA hor:zontally, about $2.5 \mathrm{~cm}$ above the medtan plane. arit is deposited above the injection closed orbit :" means of the horizoncal sepeum $S$ and the horlzonis: Lambersson septum LS upstream of the lattice quadi 1pole Q6. A vertical trim septum $T$ and the partial. iperture vertical fast k1cker $K$ bring the beam to a vi:tical landing on the Injection orbit near $Q 7$. Oniy she infection orbit is covered by the fleld region of the kicker. The injected beam is accelerated out of the kicker aperture 1nto the stack through an open fole in the magnet.

Figure 5 illustrates the sicuarion depicted is F18. 2 when the momentum offset of the iafection orbit is $i p / p *-1 \%$ and the stack is at higher momentum. If ie should be desirable to Infect at high momentum and decelerate into the stack, one may wove the kicker over the centerIIne and readjust the Injected beam trafectory horlzontally by means of the Lambertson septum LS and a horizontal trioning dipole (not shown) located between the geptum $S$ and the last transfer IIne quadrupole $Q$. The aperture of all infection ragnets (ocher than the (icker) are large enough to accept the full = I:- momentum acceptance of the ISA.

The essential parameterg of the infection magsets are summarized In Table IIf.

Table III. Infection Yagnet Parameterg

\begin{tabular}{|c|c|c|}
\hline & $\geqslant$ (orad) & $\underline{B}(T)$ \\
\hline $\begin{array}{l}\text { Kicker } 5 \\
\text { Trim Septum } \\
\text { Lambertson Septum LS } \\
\text { Septum } 5\end{array}$ & $\begin{array}{c}1.6 \\
-0.4 \\
20 \\
-50\end{array}$ & $\begin{array}{r}0.08 \\
.08 \\
.67 \\
1.3\end{array}$ \\
\hline
\end{tabular}

The septum magnets will be pulsed with a pulse duration of approximately $10^{-3}$ seconds. The fast kicker Hili have a risetime to full amplitudes of $\sim 150 \mathrm{nsec}$ to permit successive insertion of five pulge trains from the AGS with the bunch to bunch separation of 225 nsec.

\section{Tolerance Considerations}

The necessity of avolding beal dilution due to ccherent motion imposes quice stringent tolerances on Various parameters of the injection and beam stacking

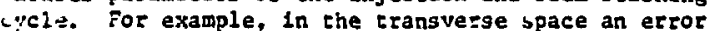
of $1:$ in the injection kicker angle will introduce coherent motion amounting to a dilution of the vertical emiccance area $\left(\leqslant-0.5 \times 10^{-6} \mathrm{rad}-\pi\right)$ by about $20 \%$ (ac the kicker $\beta_{v}=14 \mathrm{~m}$ ). There are many sources of error of this $k$ ind in the beam transfer IIne and $a$ discussion of all of them is not approprlate here. It is necessary to take two precautions: We allow for a "target zone" on the infection orbit and $1 \mathrm{n}$ the injection beam equipment which accommodaces twice the theoretical beam size and we plan to Install a transverse feedback mechanism In the ISA to damp these error oscillations down.

In longitudinal phase space it is important that all bunches be properly centered in their buckets before the stacking cycle begins: Energy error $\delta E / E$ and phase error $\delta *$ have to sat1sfy $((\delta E / E) /(\Delta E / E))^{2}+(O F / A-)^{2} \leq$ $25 \times 10^{-4}$ if the reduction in densicy, chus in cotal curtent in the circulating beam, due to these errors is to be kept below 10\%. Given the anplisudes of the deviacions in celative exergy and in phase in the nominal bunch of $\triangle E / E\left(\approx 5 \times 10^{-4}\right)$ and $\Delta=(\approx 0.6 \mathrm{rad}), 1 \mathrm{t}$ follows that the centra: snergy of Indiyidual bunches has to be correct to within $\pm 1.8 \times 10^{-5}$ and the phase to within $=21$ mrad for a dilution factor of $10 \%$. Nore that the loss in Iuminosity goes as the square of the loss in beam current: The two empty buckets mencloned before and a dilution factor of 10\% together reduce the luminosity by $26 \%$ from what it might be.

Synchrontzation of the AGS $r f$ Erequency to that of the ISA wIII use a phase locked loop. It is expected that the phase error $\dot{\theta}$. can be kept below the $=1.2^{\circ}$ colerance menctoned above. Control of the AGS magnet1s field on the ejection flat top will be by means of a closed loop Incorporating an integrated B Signal and voltage to frequency converter. A reproductbility of $\leq 10^{-4}$ in $B$ is the design goal. Any remaining dipole oscillations $1 \pi$ the IS $d$ buckets will be controlled by a feedback loop. Matching of the bunches to the buckets in the ISA will be performed in the AGS prior to extraction. Errorg will be corrected by damping coherent quactrupole bunch oscillations in the ISA. Precise control of the AGS bunch area will be necessary in addicion to intensicy control so that the optimum long1cudinal densicy for the ISA can be obtained. A study of varlous methods of programed dilution acting prior to reaching the transition energy is planned. A range of $=.5$ to $1.5 \mathrm{eV}$ sec/bunch will be the Intelal design goal.

\section{References}

1. ISABELLE Design Proposal, BNL 50718 (1978).

2. W.T. Weng, BNL, Internal Report, dGS DIV 78-? (1978).
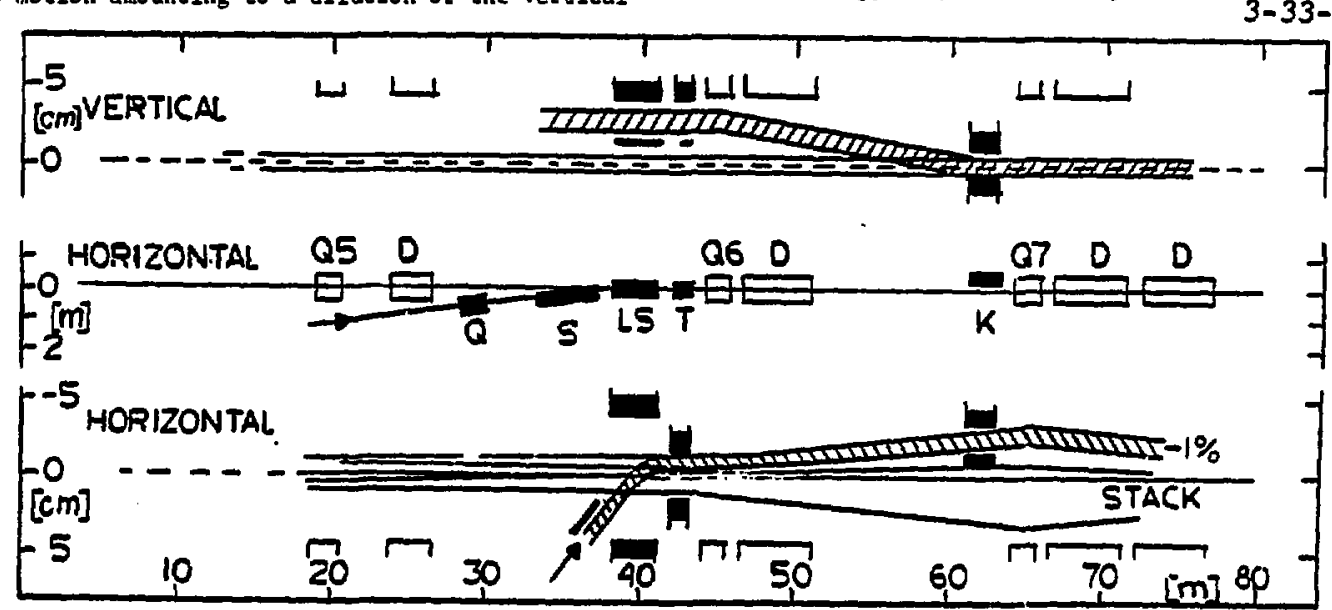

F1g, 5. Layout of the ISA infection trafectories, beam envelopes, and components. 